\title{
What kind of attention modulates the Stroop effect?
}

\author{
DEREK BESNER and JENNIFER A. STOLZ \\ University of Waterloo, Waterloo, Ontario, Canada
}

\begin{abstract}
An intersection of three literatures (skilled word recognition, spatial attention, and the Stroop effect) is addressed in a series of four experiments. The results, in conjunction with other observations, are taken to suggest that (1) the default value for spatial attention in visual word recognition is distributed across the word, (2) precuing a single letter position serves to narrow the focus of spatial attention, and (3) this reduces or prevents activation in the word recognition system. Consequently, the Stroop effect is reduced in magnitude or eliminated, depending on details of the context. Contrary to the widespread view that it reflects automatic processing, the Stroop effect is better conceptualized as reflecting the action of default settings in the word recognition and attentional systems. Some relations between consciousness, context, and control are noted.
\end{abstract}

It is clear that mental skill acquired through high levels of practice confers benefits on the performer. For example, skilled performance in a domain such as word recognition is much faster and less error prone than unskilled performance. A more contentious claim is that this speed-up carries a cost; skilled readers are said to be unable to prevent lexical and semantic analyses of words, provided that the stimulus is clear enough, bright enough, large enough, and presented for a sufficiently long duration for the reader to process it. The most famous example, provided in many papers, chapters, and textbooks, in support of this assertion is the Stroop effect (Stroop, 1935; see also MacLeod's, 1991, review). When skilled readers are asked to identify the print color of a word and explicitly instructed not to read the word, they are nonetheless typically slower and more error prone when the word references an incongruent color (e.g., the word red printed in green), as compared with the time taken to identify the color when the word references a congruent color (e.g., the word red printed in red) or a noncolor term (e.g., the word pen printed in green). Word recognition, thus, is widely viewed as automatic, in the sense that it occurs without intent and cannot be prevented (see, e.g., Anderson, 1995; Asheraft, 1994; Crowder \& Wagner, 1992; Posner \& Snyder, 1975; Rayner \& Pollatsek, 1989; Reisberg, 1997).

One difficulty with this account of mental skill as being exemplified by the Stroop effect is that it is unwarranted. It is one thing to show that skilled readers sometimes process the word despite being instructed not to but quite another to conclude that word recognition is therefore automatic, in the sense that lexical and semantic analy-

This research was supported by Grants A0998, OGP0183905, and EQP0187220 from the Natural Sciences and Engineering Council of Canada. We thank R. S. McCann for comments on a draft of the manuscript and K. Rayner, B. A. Levy, and R. Klein for their reviews. Address correspondence to D. Besner, Department of Psychology, University of Waterloo, Waterloo, ON N2L 3GI, Canada (e-mail: dbesner $(a)$ watarts.uwaterloo.ca). ses of a word are inevitably triggered by the presentation of a word. An alternative account is that, given the proper context, it is possible to modulate those processes that give rise to the Stroop effect. That is, mental processing can be contextually controlled (although not necessarily consciously). If this alternative is correct, some of the mental processes that give rise to the Stroop effect are characterized more usefully as reflecting the default settings in the word recognition and associated attention systems than as automatic (see, e.g., Bauer \& Besner, 1997; Besner \& Stolz, in press; Besner, Stolz, \& Boutilier, 1997; see also Stolz \& Besner, 1996, in press). This alternative account would also serve to realign our view of mental skills with that of perceptual-motor skills (when one watches an athlete like Michael Jordan, it is clear that skill involves a good deal of control).

The hypothesis investigated here is that a narrowing of spatial attention can modulate the word recognition processes involved in the Stroop effect. Many investigations of the Stroop effect involve the central presentation of a single color word. Spatial attention is not typically manipulated and has, therefore, been understandably neglected as a component process that might play an important role in the Stroop effect, in that one doesn't usually see theoretical discussion of factors that have not been manipulated in an experiment. In contrast, several reports in the word recognition and attention literatures point to an important role for spatial attention. We begin by briefly noting some relevant findings in these literatures.

McCann, Folk, and Johnston (1992) reported that lexical decision time to a target was strongly affected by the validity of an exogenous cue consisting of a small patch of light. Lexical decision times were faster if the target appeared in the cued location (valid cue) than if it appeared in the uncued location (invalid cue). Further, the effect of the target string's print frequency had additive effects with cuing on response time (RT). McCann et al. therefore argued that spatial attention, as indexed by exogenous cuing, is a necessary preliminary to whatever stage in the word recognition process is affected by word 
frequency. Related observations point to an important role for spatial attention within a word. We first briefly describe the word superiority effect (WSE) and then how a spatial attention manipulation affects it.

Reicher (1969) reported that a letter in a word is more accurately identified than a letter by itself in the context of a brief display followed by a pattern mask. One account of this WSE appeals to the notion of interactive activation (McClelland \& Rumelhart, 1981). The visual presentation of a word results in the cascaded activation of feature, letter, and word level representations in memory. Adjacent levels are engaged in interactive activation; activation at the word level feeds back to the letter level, increasing the probability that the letter level is sufficiently activated to support correct letter identification in the context of the two-alternative forced choice procedure. In contrast, the presentation of a single letter does not activate the word level as strongly as does the presentation of a word; hence, there is less feedback to the letter level from the word level and, consequently, weaker overall activation of the correct alternative at the letter level.

The distribution of spatial attention plays an important role in the WSE. Johnston (1981; see also Johnston \& McClelland, 1974) reported that precuing the position of a letter in the display by telling subjects which position would be probed eliminated the WSE. As Johnston noted, one natural account of this elimination of the WSE is in terms of spatial attention. We assume that the default value for spatial attention is that it is distributed across the letter positions occupied by a word (see also LaBerge, 1983). However, spatial attention can be more narrowly tuned (e.g., by precuing a single letter position) so that processing tends to focus at a particular spatial location. If spatial attention is necessary for word recognition, narrow tuning will either prevent activation in the mental representations for words or else allow for only weak activation, because fewer letters get activated initially. This account is consistent with the findings reported by Johnston (1981) and Johnston and McClelland (1974).

The implication for understanding the role of spatial attention in the Stroop effect appears straightforward. The standard Stroop effect arises, in part, because the default value for spatial attention is that it is distributed across the word. ${ }^{1}$ Put another way, if spatial attention is not distributed across the word, lexical and semantic level activation will occur in reduced form or not at ail. A Stroop effect will be, therefore, either reduced in magnitude or eliminated, as compared with cues in which spatial attention is distributed across the word.

In this vein, Besner et al. (1997) reported that the Stroop effect was eliminated when only a single letter in a color word was colored, a result that is consistent with the idea that spatial attention was narrowed, thus preventing lexical level activation. This interpretation has been offered before (see, e.g., Kahneman \& Henik, 1981), but it is open to the argument that it is not a necessary one. Indeed, Besner et al. offered a different account, one in which having to process a single colored letter leads to an activation block between lexical and semantic levels, rather than preventing activation beyond the letter level. It is, thus, unclear how the single color manipulation is related to precuing as a way of manipulating spatial attention. Given this state of affairs, the present experiments combined spatial precuing with the Stroop paradigm, in order to investigate whether narrowing the range of spatial attention would reduce or eliminate the Stroop effect.

\section{EXPERIMENTS 1 AND 2}

\section{Method}

Subjects. Twenty-two University of Waterioo undergraduate students were paid to participate in Experiment 1, and 34 in Experiment 2. All had normal or corrected-to-normal vision, and all were native English speakers.

Stimulus materials and list construction. Experiments 1 and 2 were identical in all respects, except that the stimulus display in Experiment 2 contained a blank character space between each letter. This was done to investigate whether larger spaces between adjacent letters would lead to improved spatial selection.

The stimuli in these experiments were the words red $(9 \mathrm{~mm}$ long $\times 5 \mathrm{~mm}$ high), blue (12 $\mathrm{mm}$ long $\times 5 \mathrm{~mm}$ high), green $(15 \mathrm{~mm}$ long $\times 4 \mathrm{~mm}$ high), and yellow (18 $\mathrm{mm}$ long $\times 6 \mathrm{~mm}$ high), printed in standard MEL lowercase font. The stimuli were printed in the Micro Experimental Lab (MEL2; Schneider, 1988) colors: red (RGB: $42,0,0$ ), blue (RGB: 0, 0, 42), green (RGB: 0, 42, 0), and yellow (RGB: 63,63,21), according to the appropriate congruency condition, as described below.

The experiment proper contained 256 trials. Half of the trials were congruent trials, with the target word and ink color displaying the same color. The other 128 trials were incongruent trials in which the color word and ink referenced different colors. Half of each of the congruent and incongruent trials were presented in one color. For the other half of the congruent and incongruent trials, two colors were used per target word. One letter (the odd one out) was displayed in one of the four colors, and the remaining letters were all displayed in one of the remaining three colors.

The experiment also contained a cuing manipulation. For the 128 stimuli ( 64 congruent and 64 incongruent) displayed in one ink color, half were cued with a white arrow (RGB: 63,63,63) appearing both one line above and one line below a single letter of the target word. The arrow appearing above the letter(s) was character 25 from the standard ASCII character set. The arrow appearing below the letter(s) was character 24 from the standard ASCII character set. Both arrows measured $4.5 \mathrm{~mm}$ high $\times 2.5 \mathrm{~mm}$ wide. The remaining half of the stimuli painted in a single color had all letters cued (i.e., arrows appeared both above and below all the letters in the target display).

For the 128 odd color out displays ( 64 congruent and 64 incongruent), all trials had only one letter cued. Sixty-four odd one out stimuli ( 32 congruent and 32 incongruent) had arrow cues appearing above and below the odd color out letter. For the other 64 odd color out stimuli ( 32 congruent and 32 incongruent), a letter that was not the odd one out was cued.

Thus, each stimulus list was comprised of 32 congruent, singlecolor, all-cued trials; 32 congruent, single-color, one-letter-cued trials; 32 congruent, two-color, odd-one-out-cued trials; 32 congruent, two-color, non-odd-one-out-cued trials; 32 incongruent. single-color, all-cued trials; 32 incongruent, single-color, one-letter-cued trials; 32 incongruent, two-color, odd-one-out-cued trials, and 32 incongruent, two-color, non-odd-one-out-cued trials.

All trial types were displayed using all combinations of ink color and target word. Selection of ink color and target word was done randomly, and without replacement, from a pool containing all pos- 
sible combinations of conditions, ink color, and target words, with the constraint that, in the two-color displays, congruent was defined as the word matching the cued letter's color. Furthermore, the position of the odd one out letter and of the cue in the single-letter-cued conditions was varied so that they appeared equally often across all parts of the target words (i.e., beginning, middle, and end).

A set of 64 practice trials was constructed to meet the same constraints outlined above. The practice set preceded the experiment proper.

Procedure. The subjects were tested individually, seated approximately $45 \mathrm{~cm}$ from a computer monitor. Task instructions were displayed on the monitor and were also relayed verbally. Stimuli were displayed on a Microscan 4V/ADI color monitor controlled by MEL2 software implemented in a Vault Pentium 100 computer.

Each trial began with the appearance of the arrow cues, either cuing all letter positions (in the all-cued conditions) or cuing a single letter position. Following a $125-\mathrm{msec}$ stimulus onset asynchrony (SOA), the target word appeared, printed in the appropriate color(s). The target and cue arrows remained on the screen until the subjects responded. The subjects were instructed to indicate the color of the cued letter(s). Responses were made by depressing a key covered with an appropriately colored piece of paper with fingers on the left or the right hand. The colored pieces of paper covered the " $z$," " $x$," ">," and "/" keys, indicating red, blue, yellow, and green, respectively. A response initiated a 400 -msec intertrial interval, during which the computer monitor was blank. The subjects were instructed to perform as quickly and as accurately as possible.

\section{Results}

Trials on which an error was committed were discarded from the RT analysis. RTs to correct responses were first subjected to a recursive trimming procedure in which the criterion cutoff for outlier removal was established independently for each subject, for each condition, by reference to the sample size in that cell (Van Selst \& Jolicoeur, 1994). This resulted in the exclusion of $2.5 \%$ of the correct RT data in Experiment 1 and $2.6 \%$ in Experiment 2. The remaining RT and associated error data' can be seen in Table 1.

Our initial interest concerns the conditions in which the display appears in a single color, because it allows us to compare the same target displays under conditions in which only a single letter position is cued and under conditions in which all the letters positions are cued. A 2 (congruent vs. incongruent) $\times 2$ (single letter cued vs. all letters cued) analysis of variance on the RT data yielded a main effect of congruency $\left[F(1,21)=56.6, M S_{\mathrm{e}}=\right.$ $4,058, p<.001]$, no main effect of cue type $(F<1)$, and the expected interaction in which the Stroop effect is smaller in the single-letter-cued condition than in the allletters-cued condition $\left[F(1,21)=5.6, M S_{\mathrm{e}}=2,301, p<\right.$ $.05]$. The same pattern is observed in the RT data of Experiment 2 . There was a main effect of congruency $\left[F(1,33)=53.02, M S_{\mathrm{e}}=5,710, p<.001\right]$, no main effect of cuing $\left[F(1,33)=1.45, M S_{\mathrm{e}}=4,416, p>.20\right]$, and an interaction between cuing and congruency $[F(1,33)=$ $\left.11.4, M S_{\mathrm{e}}=3,269, p<.001\right]$. The error data produce the same pattern as the RT data in both experiments.

The multicolor displays also produced a Stroop effect. Congruent trials were marginally faster than incongruent trials in Experiment $1\left[F(1,21)=3.2, M S_{\mathrm{e}}=4,929, p<\right.$ $.09]$ and significantly so in Experiment $2[F(1,33)=$ 12.6, $\left.M S_{\mathrm{e}}=3,711, p<.001\right]$. RTs were faster when the cued letter position indicated the odd color rather than the nonodd color in both experiments [Experiment 1, $F(1,21)=9.7, M S_{\mathrm{e}}=3,821, p<.005$; Experiment 2, $\left.F(1,33)=12.6, M S_{\mathrm{e}}=3,711, p<.001\right]$, but the interaction between congruency and type of multicolored display was not significant in Experiment $1(F<1)$ or in Experiment $2\left[F(1,33)=1.6, M S_{\mathrm{e}}=3,531, p>.05\right]$. The error data were again consistent with the RT data,

Table 1

Mean Response Times (RT, in Milliseconds) and Errors (\% E) According to Conditions in Experiments 1-4

\begin{tabular}{|c|c|c|c|c|c|c|c|c|c|c|c|c|c|c|}
\hline \multirow[b]{4}{*}{ Color Condition } & \multicolumn{14}{|c|}{ Spatial Cue } \\
\hline & \multicolumn{6}{|c|}{ All Letters } & \multicolumn{8}{|c|}{ One Letter } \\
\hline & \multicolumn{3}{|c|}{ RT } & \multicolumn{3}{|c|}{$\% \mathrm{E}$} & \multicolumn{4}{|c|}{ RT } & \multicolumn{4}{|c|}{$\% \mathrm{E}$} \\
\hline & I & $\mathrm{C}$ & $d$ & I & $\mathrm{C}$ & $d$ & $\mathrm{I}$ & $\mathrm{C}$ & $\mathrm{N}$ & $d$ & 1 & $\mathrm{C}$ & $\mathrm{N}$ & $d$ \\
\hline \multicolumn{15}{|c|}{ Experiment $1(n=22)$} \\
\hline One color & 897 & 771 & 126 & 3.6 & 1.7 & 1.9 & 866 & 788 & & 78 & 1.6 & 1.7 & & -0.1 \\
\hline \multicolumn{15}{|l|}{ Two colors } \\
\hline Main color cued & & & & & & & 952 & 919 & & 33 & 3.4 & 2.8 & & 0.6 \\
\hline Odd color cued & & & & & & & 905 & 884 & & 21 & 2.1 & 1.8 & & 0.3 \\
\hline \multicolumn{15}{|c|}{ Experiment $2(n=34)$} \\
\hline One color & 860 & 732 & 128 & 4.0 & 1.7 & 2.3 & 813 & 751 & & 62 & 3.5 & 2.8 & & 0.7 \\
\hline Two colors & & & & & & & & & & & & & & \\
\hline Main color cued & & & & & & & 880 & 829 & & 51 & 4.4 & 3.1 & & 1.3 \\
\hline Odd color cued & & & & & & & 830 & 805 & & 25 & 2.9 & 2.5 & & 0.4 \\
\hline \multicolumn{15}{|c|}{ Experiment $3(n=45)$} \\
\hline \multicolumn{15}{|l|}{ Two colors } \\
\hline Main color cued & & & & & & & 857 & & 839 & 18 & 2.6 & & 2.9 & -0.3 \\
\hline Odd color cued & & & & & & & 835 & & 834 & 1 & 2.0 & & 2.9 & -0.9 \\
\hline \multicolumn{15}{|c|}{ Experiment $4(n=35)$} \\
\hline Two colors-odd color cued & & & & & & & 820 & & 811 & 9 & 2.9 & & 3.3 & -0.4 \\
\hline
\end{tabular}

Note $C$, congruent display; I, incongruent display; $\mathrm{N}$, neutral baseline display; $d$, difference score (Experiments 1 and 2 , $\mathrm{I}-\mathrm{C}$; Experiments 3 and $4,1-\mathrm{N}$ ). 
but the interaction was not significant in either experiment $(F \mathrm{~s}<1)$.

\section{Discussion}

The results of Experiments 1 and 2 are straightforward. The Stroop effect in the RT data is reduced when only a single letter position is cued, as compared with when all the letter positions in the word are cued. If the cuing procedure indexes spatial attention, as is standardly assumed in the attention literature, the reduction in the magnitude of the Stroop effect can be understood in terms of the proposition that word recognition is dependent on the distribution of spatial attention across the word and that narrowing the bandwidth of spatial attention reduces the efficiency of these word recognition processes or prevents them from operating.

Why doesn't spatial cuing eliminate, rather than just reduce, the Stroop effect in Experiments 1 and 2, in accordance with Johnston's (1981) observation that the WSE is eliminated when subjects are told to focus on a particular letter position because it will be probed? Four aspects of Experiments 1 and 2 merit consideration in this regard.

One possibility is that subjects do not always have an opportunity to focus spatial attention on only the cued letter before the display appears. A blank character space, therefore, was inserted between each letter in Experiment 2 in an attempt to increase spatial selectivity. Although Experiment 2 produced the same interaction as that in Experiment 1, there was little evidence that this manipulation increased its magnitude relative to Experiment 1, as one would expect if spatial attention were more selective. Still, cue duration was not manipulated; we therefore reserve judgment as to whether spatial selection has been completed before the target appeared.

A second consideration is that congruent trials are present in the experiment. Arguably, these trials should be eliminated in favor of a neutral baseline condition, because including congruent trials encourages subjects to read the word, even though it produces a cost on incongruent trials. Both Lowe and Mitterer (1982) and Tzelgov, Henik, Sneg, and Baruch (1996) report that increasing the proportion of congruent trials increases the magnitude of the interference effect (incongruent minus neutral), a result that is consistent with this view.

A third consideration concerns the nature of the manipulation that encourages subjects to pay attention to the cue on the single-color trials. This was accomplished by including multicolor trials on which the subject must pay attention to the cue in order to make a correct response. This is a weak manipulation, insofar as the single-color trials are concerned, because there is nothing in these trials that requires subjects to use the cue. Subjects arguably do use the cue on these trials at least some of the time, given that the Stroop effect is reduced in magnitude, relative to the condition that cues all letters. The problem is that it is difficult to determine whether sub- jects always used the single-letter cue or whether they sometimes abandon relying on it when they detect that the display is a uniform color. ${ }^{2}$

Another important consideration concerns how "the subject's" information processing machinery might view the task. On $3 / 4$ of the trials, the correct response is associated with the color that most letters appear in. This fact might promote the use of a heuristic in which letters that appear in the same color are sometimes packaged together for processing (the Gestalt principle of similarity). ${ }^{3}$ If several letters are processed together despite the cue, such processing - through interactions between letter level, word level, and semantics-might provide sufficient activation to produce a Stroop effect, even on the multicolor trials in which the single-letter cue must be attended. It is interesting that the Stroop effect is smallest, in both Experiments 1 and 2, when the cue indicates the odd color out on a multicolor trial, as compared with when the cue indicates a color shared with other letters in the same display. This packaging is less likely to occur in the odd color out condition. Thus, multicolor displays themselves may provide an even more powerful tool for exploring the role of spatial attention in the Stroop effect, as compared with just using them as a background context to examine what happens on single-color trials.

\section{EXPERIMENTS 3 AND 4}

Experiments 3 and 4 focus exclusively on multicolor displays, because here the subject must use the cue to guide a response. Thus, a single-letter cue appeared on all trials. In addition, the congruent trials were replaced with neutral nonword controls (as used previously by Besner et al., 1997) in order to eliminate any benefit from reading the word. In Experiment 3, the position occupied by the odd color out was cued on half the trials. On the remaining trials, a position was cued in which the letter's color was the same as all the other letters but one. If the packaging by similarity heuristic advanced earlier is operative, Experiment 3 may produce a Stroop effect when the cued letter position is occupied by the same color as most of the other letters in the display. In contrast, the odd color out condition ought to produce little or no Stroop effect, because the packaging heuristic should not be operative here. In Experiment 4, the subjects saw the same target displays as those in Experiment 3, but the odd color out was cued on every trial. This experiment encourages spatial selectivity and, thus, the prediction that little or no Stroop effect will be observed.

\section{Method}

Subjects. Forty-five University of Waterloo undergraduate students were paid to participate in Experiment 3, and 35 in Experiment 4. All had normal or corrected-to-normal vision, and all were native English speakers.

Stimulus materials and list construction. The multicolor displays for both Experiment 3 and Experiment 4 were generated in the same way as those for Experiments 1 and 2 . There were 32 practice 
and 128 test trials in Experiment 3 and 32 practice and 64 test trials in Experiment 4. Cuing was accomplished in the same way as in Experiments 1 and 2 in both Experiment 3 and Experiment 4, except that, on all trials, only a single letter position was cued. In both Experiment 3 and Experiment 4, congruent trials were discarded. and neutral nonword controls, consisting of the strings ret, blat, yenile, and grend, were substituted. These strings preserved the letter length of the words they replaced, as well as the two first letters (see Besner et al., 1997, for a discussion of the appropriateness of such controls).

\section{Results}

The results can be seen in Table 1. Using the same trimming procedure as that in Experiments 1 and 2, 1.9\% of the correct RTs were discarded as outliers in Experiment 3, and $2.8 \%$ in Experiment 4 . In Experiment 3, the incongruent trials were $18 \mathrm{msec}$ slower than control trials when the cued letter was the same color as all the other letters but one $[t(44)=2.47, p<.02]$. There was no significant Stroop effect in the RT data from the odd color out condition in Experiment $3[t(44)=0.12, p>$ $.89]$ or in Experiment $4[t(34)=1.09, p>.25]$.

The error pattern was one in which the neutral condition produced slightly more errors than the incongruent condition in both Experiment 3 and Experiment 4 . The largest difference was less than $1 \%$; only the odd letter out condition in Experiment 3 approached significance $[t(44)=1.71, p<.09]$.

Finally, the data from the odd color out condition were combined across Experiments 3 and 4 to increase power. There was no significant Stroop effect in the RT data, $(t<1)$. The $0.69 \%$ error effect (in the wrong direction) was not significant $[t(79)=1.58, p>.10]$.

\section{Discussion}

Experiment 3 produced a small (18-msec) Stroop effect when the cued color was the same as all the other letters but one. This result is consistent with the conjecture that subjects sometimes engage in a packaging heuristic such that letters that are the same color as the cued letter tend also to get processed. In contrast, the odd color out condition produced no significant Stroop effect in Experiment 3, Experiment 4, or when the data were combined across experiments. ${ }^{4}$

\section{GENERAL DISCUSSION}

The pattern of results observed across experiments is quite consistent. In Experiments 1 and 2, precuing just one letter position in single-color displays reduced the magnitude of the Stroop effect, relative to the same displays in which all the letters were precued. Experiments 1,2 , and 3 also revealed a pattern in which the multicolor displays yielded a smaller Stroop effect when the odd color out was cued than when a color common to all letters but one was cued. Finally, Experiments 3 and 4 (individually and combined) failed to produce a significant Stroop effect in the odd color out condition, as was predicted by the view that narrowed spatial attention would be most efficient in this condition.
Taken together, these results are inconsistent with the widespread claim that word recognition is an automatic process, in the sense that lexical/semantic analyses are inevitably triggered by stimulus presentation. Instead, they are consistent with the view that contextual control, in the form of the distribution of spatial attention across a word, plays a critical role in its processing. Spatial attention's default value, likely triggered by the onset of a stimulus (or stimuli), is distributed across the stimulus. Precuing a single letter position serves to deploy spatial attention more narrowly, so that subsequent word recognition processes operate less efficiently or not at all, as indexed by a reduction or elimination of the Stroop effect. 5,6

\section{Unconscious but Not Automatic}

Automatic processes are often characterized as unconscious, as occurring without intent, and as not being subject to control (see, e.g., Posner \& Snyder, 1975). It is easy to slide from one assumption to the other (the Stroop effect occurs without intent because it is unconscious; and, the Stroop effect is unconscious because it can't be controlled) but such claims are best treated cautiously (e.g., some things that are clearly conscious, such as obsessive thoughts, and the phenomenon of "alien hand" resist control).

It seems quite uncontentious to characterize much cognitive processing as unconscious, in the sense that we are often aware of the products of processing rather than the processing. In that vein, we see no reason to abandon the assumption that many of the mental processes involved in the Stroop effect are typically unconscious. However, all of these processes are not automatic; contextual control can occur without consciousness. To put the argument another way, consciousness need not imply control, and control need not imply consciousness.

\section{REFERENCES}

ANDERSON, J. (1995). Cognitive psychology and its implications. New York: Freeman.

AshCraft, M. H. (1994). Human memory. and cognition. New York: Harper Collins.

Bauer, B., \& Besner, D. (1997). Processing in the Stroop task: Mental set as a determinant of performance. Canadian Journal of Experimental Psvchology, 51, 61-68.

BESNER, D., \& STOLZ, J. A. (in press). Unconsciously controlled processing: The Stroop effect reconsidered. Psychonomic Bulletin \& Review'.

Besner, D., Stolz, J. A., \& Boutilier, C. (1997). The Stroop effect and the myth of automaticity. Psychonomic Bulletin \& Review, 4, 221-225.

BRUNN, J. L., \& FARAH, M. J. (1991). The relation between spatial attention and reading: Evidence from the neglect syndrome. Cognitive Neuropsychology, 8, 59-75.

Cohen, J., \& Huston, T. A. (1994). Progress in the use of interactive models for understanding attention and performance. In C. Umiltà \& M. Moscovitch (Eds.), Attention and performance XV: Conscious and nonconscious information processing (pp. 453-476). Cambridge. MA: MIT Press, Bradford Books.

Crowder, R. G., \& Waciner, R. F. (1992). The psychologl of reading. New York: Oxford University Press.

Fot.K, C. L., Rfminciton, R. W.. \& Johnston, J. C. (1993). Contingent attentional capture: A Reply to Yantis (1993). Journal of Experimenlal Psichologl: Human Perception \& Performance, 19, 682-685.

JoH.NSTON. J. C. (1981). Effects of advance precueing of alternatives on 
the perception of letters alone and in words. Journal of Experimental Psychology: Human Perception \& Performance, 7, 560-572.

Johnston, J. C., \& MCClelland, J. L. (1974). Perception of letters in words: Seek not and ye shall find. Science, 184, 1192-1194.

Kahneman, D., \& Henik, A. (1981). Perceptual organization and at tention. In M. Kubovy \& J. R. Pomerantz (Eds.), Perceptual organization (pp. 181-211). Hillsdale, NJ: Erlbaum.

LABERGE, D. (1983). Spatial extent of attention to letters and words. Journal of Experimental Psychology: Human Perception \& Performance, 9, 371-379.

Lowe, D. G., \& MitTerer, J. O. (1982) Selective and divided attention in a Stroop task. Canadian Journal of Psychology, 36, 684-700.

MACLEOD, C. M. (1991). Half a century of research on the Stroop effect: An integrative review. Psychological Bulletin, 109, 163-203.

McCann, R. S., Folk, C. L., \& Johnston, J. C. (1992). The role of spatial attention in visual word processing. Journal of Experimental Psychology: Human Perception \& Performance, 18, 1015-1029.

McClelland, J. L., \& Rumelhart, D. E. (1981). An interactive activation model of context effects in letter perception: Part 1. An account of basic findings. Psychological Review, 88, 375-407.

Posner, M. I., \& SNydER, C. R. R. (1975). Attention and cognitive control. In R. L. Solso (Ed.), Information processing and cognition: The Loyola Symposium (pp. 55-85). Hillsdale NJ: Erlbaum.

RAYNer, K., \& Pollatsek, A. (1989). The psychology of reading. Englewood Cliffs, NJ: Prentice-Hall

REICHER, G. M. (1969). Perceptual recognition as a function of meaningfulness of stimulus material. Journal of Experimental Psychology, 81, 275-280

REISBERG, D. (1997). Cognition: Exploring the science of the mind. New York: Norton.

SCHNEIDER, W. (1988). Micro Experimental Laboratory: An integrated system for IBM PC compatibles. Behavior Research Methods, Instruments, \& Computers, 20, 206-217.

STOLZ, J. A., \& BESNER, D. (1996). The role of set in visual word recognition: Activation and activation blocking as non-automatic processes. Journal of Experimental Psychology: Human Perception \& Performance, 22, 1166-1177

STOLZ, J. A., \& BESNER, D. (in press). Levels of representation in visual word recognition: A dissociation between morphemic and semantic processing. Journal of Experimental Psychology: Human Perception \& Performance.

STroop, J. R. (1935). Studies of interference in serial verbal reactions. Journal of Experimental Psychology, 18, 643-661.

Tzelgov, J., Henik, A., SNeg, R., \& Baruch, O. (1996). Unintentional reading via the phonological route: The Stroop effect with cross script homophones. Journal of Experimental Psychology: Learning, Memory, \& Cognition, 22, 336-349.

VAN SELST, M., \& Jolicoeur, P. (1994). A solution to the effect of sample size on outlier elimination. Quarterly Journal of Experimental Psychology, 47A, 631-650.

YANTIS, S. (1993). Stimulus-driven attentional capture and attentional control settings. Journal of Experimental Psychology: Human Perception \& Performance, 19, 676-681.

YanTIS, S. (1996). Attentional capture in vision. In A. F. Kramer, M. G. H. Coles, \& G. D. Logan (Eds.), Converging operations in the study of visual selective attention (pp. 45-76). Washington, DC: American Psychological Association.

\section{NOTES}

1. McCann et al. (1992) do not mention either Johnston's (1981) or Johnston and McClelland's (1974) findings in their discussion of the literature on spatial attention and word recognition. However, Johnston does briefly discuss his findings in the context of the Stroop effect. Unfortunately, neither of these findings has been promulgated (e.g., the major review of the Stroop literature makes no mention of them).

2. There has been some debate as to whether an abrupt onset cue is a sufficient condition to attract spatial attention (e.g., see Folk, Remington, \& Johnston, 1993, vs. Yantis, 1993; see also Yantis, 1996). We note that there was no hint that single-letter cuing reduced the magnitude of the Stroop effect when we tested subjects on a version of Experiments 1 and 2 that did not include multicolor displays. That is, when nothing in the experiment required subjects to use the cue, there was no evidence that subjects used it.

3. The question is often raised as to why subjects don't just focus on a single letter in order to avoid the Stroop effect in the standard singlecolor preparation. It seems likely that the packaging by similarity heuristic and the presence of congruent trials combine to produce a Stroop effect.

4. We emphasize that the Stroop effect is statistically eliminated. A more powerful experiment might detect a small effect. It should be noted that the (nonsignificant) $9-\mathrm{msec}$ effect in Experiment 4 arises, in large part, from the slowest subject in the incongruent condition, who produced a $127-\mathrm{msec}$ Stroop effect. If this subject is discarded, the mean estimate of the Stroop effect shrinks to $5 \mathrm{msec}$.

5. Cohen and Huston's (1994) interactive activation account of spatial attention and word recognition makes no mention of McCann et al.'s (1992) observation that cuing and word frequency have additive effects on RT in lexical decision. On the face of it, McCann et al.'s additive stages model provides a better account of this data than does the interactive activation account. However, it seems likely that both classes of explanation have merit. For example, under conditions of gross spatial uncertainty, spatial attention might need to be shifted before some subsequent word recognition stage can take up information. In contrast, when there is little or no spatial uncertainty concerning where the target string appears (as in the present paradigm), spatial attention and word recognition could sometimes be engaged in interactive activation. It is likely that part of the answer depends on what the subject is trying to do. Here, the subject tries to ignore the stimulus, but in other situations, such as the line bisection task carried out in the presence of an irrelevant word, feedback from the lexical/semantic level helps to overcome the deficits seen in unilateral neglect (see Brunn \& Farah, 1991).

6 . It is worth stressing that the strength of the default set (of reading the word) is assumed to be a parameter that interacts with the context For example, we would not be surprised if, in the context of a naming task, some of the present experiments produced only a reduction in the magnitude of the Stroop effect, rather than eliminating it. To put it another way, we would resist the argument that such a finding is conclusive evidence that word reading is partly automatic.

(Manuscript received December 19, 1997; revision accepted for publication March 12, 1998. ) 